\title{
Giant "heart appearance-like sign" on MRI in bilateral ponto-medullary junction infraction: case report
}

\author{
Zhi-Hua Zhou*, Yun-Fan Wu², Wei-Feng Wu' ${ }^{1}$ Ai-Qun Liu', Qing-Yun Yu', Zhong-Xing Peng ${ }^{1}$ and Ming-Fan Hong ${ }^{1}$
}

\begin{abstract}
Background: Bilateral medial medullary infarction (MMI) is uncommon and bilateral medial pons infarction (MPI) is even rarer. "Heart appearance" on magnetic resonance imaging (MRI) is a characteristic presentation of bilateral medial medullary infarction (MMI).

Case presentation: We present 67-year-old Chinese diabetic and hypertensive female patient affected with "heart appearance-like" infarction in bilateral ponto-medullary junction on MRI. Abnormal signal was observed in the bilateral ponto-medullary junction on T1, T2, fluid-attenuated inversion recovery and apparent diffusion coefficient (ADC). The whole brain digital subtraction angiography (DSA) showed the basilar artery and vertebral artery remained intact. Therefore, we speculated that the bilateral ponto-medullary junction infarction might be caused by the deep perforating branch of the basilar artery.

Conclusions: As far as we know, the "heart appearance-like" infraction in bilateral ponto-medullary junction was not reported. Our case also suggests that bilateral ischemic infraction involvement of the medulla and pon is possible even in the context of an intact basilar artery.
\end{abstract}

Keywords: Medial medullary infarction (MMI), Medial pons infarction (MPI), Ponto-medullary junction infraction, Heart appearance, Magnetic resonance image (MRI), Digital subtraction angiography (DSA)

\section{Background}

Bilateral medial medullary infarction (MMI) is uncommon, accounting for $0.5-1.51 \%$ of all strokes [1-3]. Bilateral medial pons infarction (MPI) is even rarer, accounting for $<10 \%$ of all pontine infarctions [4]. "Heart appearance" on magnetic resonance imaging (MRI) is a characteristic presentation of bilateral medial medullary infarction (MMI) [5-7]. "Heart appearance" of the bilateral medial pons infarction (MPI) has been described rarely $[4,8,9]$.

\footnotetext{
*Correspondence: zhouzh20051103@163.com

'Department of neurology, The first affiliated hospital, School of Clinical Medicine of Guangdong Pharmaceutical University, Guangzhou, Guangdong, China

Full list of author information is available at the end of the article
}

As far as we know, "heart appearance-like" infarction of the bilateral ponto-medullary junction has not been reported. In this paper, we present a patient affected with "heart appearance-like" infarction of the bilateral ponto-medullary junction on MRI and the whole brain digital subtraction angiography (DSA) showed the basilar artery (BA) and bilateral vertebral artery (VA) remained intact.

\section{Case presentation}

A 67-year-old Chinese diabetic and hypertensive female patient presented with sudden onset vertigo with nausea and vomiting 4 days ago. Then she presented with sudden onset of right hemiparesis 2 days ago and developed rapidly quadriplegia (upper and lower limbs with grade 0 power), dysarthria, bilateral facial

(c) The Author(s). 2020 Open Access This article is licensed under a Creative Commons Attribution 4.0 International License, which permits use, sharing, adaptation, distribution and reproduction in any medium or format, as long as you give appropriate credit to the original author(s) and the source, provide a link to the Creative Commons licence, and indicate if changes were made. The images or other third party material in this article are included in the article's Creative Commons licence, unless indicated otherwise in a credit line to the material. If material is not included in the article's Creative Commons licence and your intended use is not permitted by statutory regulation or exceeds the permitted use, you will need to obtain permission directly from the copyright holder. To view a copy of this licence, visit http://creativecommons.org/licenses/by/4.0/ The Creative Commons Public Domain Dedication waiver (http://creativecommons.org/publicdomain/zero/1.0/) applies to the data made available in this article, unless otherwise stated in a credit line to the data. 
weakness. Her eyes moved normally and no diplopia. She had no history of smoking or drinking. On physical examination, the temperature was $36.8^{\circ} \mathrm{C}$, the pulse 76 beats per minute, and the blood pressure $165 / 95 \mathrm{mmHg}$. Detailed neurological examinations revealed quadriplegia, dysarthria, bilateral facial weakness, bilateral positive Babinski's sign. The pupils were equal and reactive. Corneal reflexes were present and there was no gaze palsy and nystagmus, scoring 24 on the National Institute of Health Stroke Scale (NIHSS). On admission, laboratory findings indicated she had abnormal fasting blood sugar, HbA1c, total cholesterol (TC), triglyceride (TG), low-density lipoprotein cholesterol (LDL-c), uric acid. Detailed results were shown in Table 1. Twenty four hours Holter electrocardiography showed sinus rhythm without ST$\mathrm{T}$ segment change and occasional premature atrial contractions (22 times within $24 \mathrm{~h}$ ). Echocardiography showed mild mitral valve regurgitation and the left ventricular ejection fraction was $68 \%$. Color Doppler flow imaging examination showed a mild resistance index of the intracranial segment of the vertebral artery (VA) and BA.

Cranial magnetic resonance imaging (MRI) brain diffusion-weighted imaging at $3.0 \mathrm{~T}$ revealed a giant heart-shaped hyperintensity area ("heart appearance-like sign") on both sides in the ventral ponto-medullary junction [Fig. 1]. Abnormal signal was observed in the same region by $\mathrm{T} 1, \mathrm{~T} 2$, fluid-attenuated inversion recovery

Table 1 Laboratory findings in the patient

\begin{tabular}{lll}
\hline Laboratory tests & Results & Normal range \\
\hline Fasting blood sugar & $12.6 \mathrm{mmol} / \mathrm{L}$ & $3.89-6.1 \mathrm{mmol} / \mathrm{L}$ \\
$2 \mathrm{~h}$ postprandial blood sugar & $16.9 \mathrm{mmol} / \mathrm{L}$ & $<7.8 \mathrm{mmol} / \mathrm{L}$ \\
HbA1c & $12.5 \%$ & $4-6 \%$ \\
Total cholesterol (TC) & $6.55 \mathrm{mmol} / \mathrm{L}$ & $3.5 \sim 5.69 \mathrm{mmol} / \mathrm{L}$ \\
Triglyceride (TG) & $2.36 \mathrm{mmol} / \mathrm{L}$ & $0.45 \sim 1.70 \mathrm{mmol} / \mathrm{L}$ \\
Low density lipoprotein & $3.82 \mathrm{mmol} / \mathrm{L}$ & $<3.12 \mathrm{mmol} / \mathrm{L}$ \\
cholesterol (LDL-C) & & \\
High density lipoprotein & $0.74 \mathrm{mmol} / \mathrm{L}$ & $0.7 \sim 2.0 \mathrm{mmol} / \mathrm{L}$ \\
cholesterol (HDL-C) & & \\
Uric acid & $625 \mathrm{umol} / \mathrm{L}$ & $90 \sim 360 \mathrm{umol} / \mathrm{L}$ \\
Homocysteine & 7.36 & $5 \sim 15 \mu \mathrm{mol} / \mathrm{L}$ \\
Prothrombin time (PT) & $13.5 \mathrm{~s}$ & $11.0 \sim 15.0 \mathrm{~s}$ \\
Activated partial thromboplastin & $32.7 \mathrm{~s}$ & $28.0 \sim 45.0 \mathrm{~s}$ \\
time (APTT) & & \\
Thrombin time (TT) & $17.8 \mathrm{~s}$ & $14.0 \sim 21.0 \mathrm{~s}$ \\
International normalized & 1.01 & $0.8 \sim 1.2$ \\
ratio (INR) & & $60 \sim 140 \%$ \\
Protein C & $96 \%$ & $63.5 \sim 149 \%$ \\
Protein S & $98 \%$ & \\
\hline
\end{tabular}

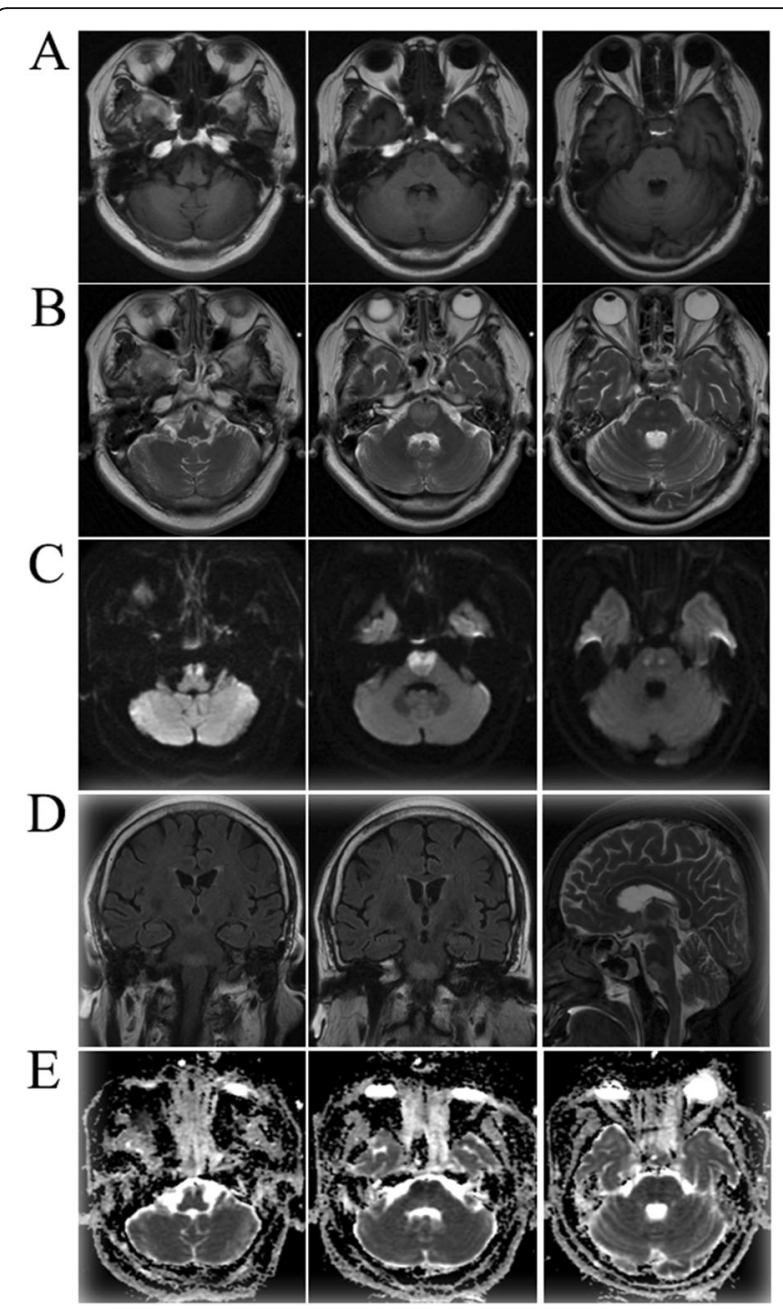

Fig. 1 Cranial magnetic resonance imaging (MRI) indicated the giant "heart appearance" on the both sides in the ventral ponto-medullary junction. a, axial T1-MRl; b, axial T2-MRl; c, axial diffusion-weighted image MRI (DWI); $\mathbf{d}$, coronal fluid attenuated inversion recovery (FLAIR) and Sagittal T2-MRI; e, axial apparent diffusion coefficient map MRI (ADC). The "heart appearance" lesion shows hypointensity on $\mathrm{T} 1$ and $A D C$, hyperintensity on $\mathrm{T} 2, \mathrm{DWI}$ and FLAIR, indicating, in conjunction with the finding on DWl, that the lesion is a subacute infarct

and apparent diffusion coefficient (ADC). On the basis of these findings, the patient was diagnosed to be having an acute bilateral ponto-medullary junction infarction. Next, we executed the detection of whole brain digital subtraction angiography (DSA) for the patient and DSA showed the basilar artery and vertebral artery remained intact [Fig. 2]. Therefore, we speculated that the bilateral ponto-medullary junction infarction might be caused by the deep perforating branch of the basilar artery. The patient was treated with Aspirin $(100 \mathrm{mg} / \mathrm{d})$ and rehabilitation was initiated. Six months later, the patient still had quadriplegia (upper and lower limbs with grade 2 power), dysarthria, bilateral facial weakness and nasal feeding. 

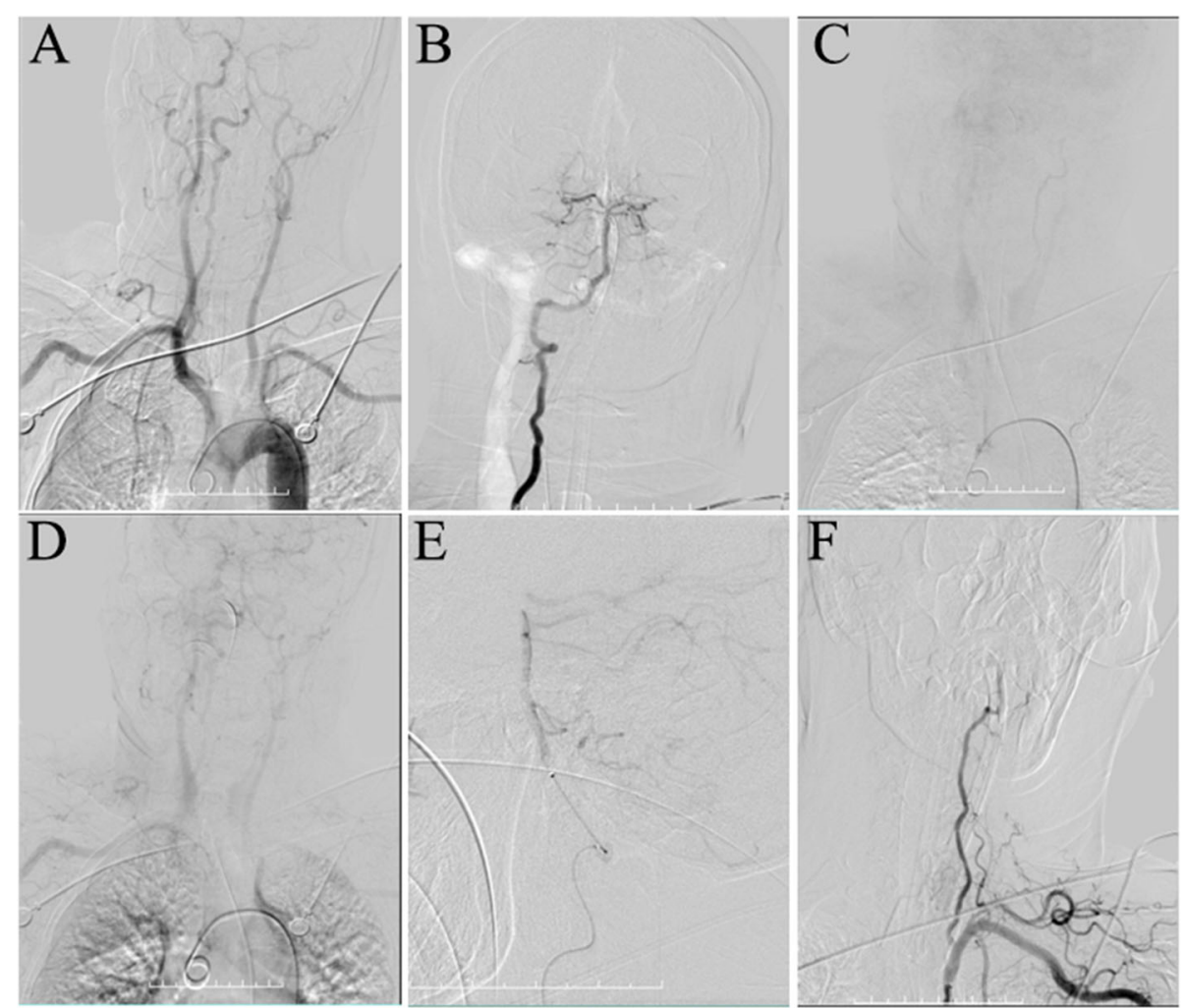

Fig. 2 Digital subtraction angiography (DSA) indicated the vertebral artery and the basilar artery remains intact despite the bilateral involvement of the ponto-medullary junction. The basilar artery and the right vertebral artery are intact $(\mathbf{a}, \mathbf{b})$. The left vertebral artery is slender $(\mathbf{a}, \mathbf{c}, \mathbf{d}, \mathbf{e}, \mathbf{f})$

\section{Discussion and conclusions}

Bilateral MMI or bilateralis MPI is a rare stroke syndrome $[4,10]$. Recently, the "heart appearance" infraction in bilateral medial medullary and bilateral pons has been described gradually $[5,8,9]$. Here we present a $67-$ year-old Chinese diabetic and hypertensive female patient affected with "heart appearance-like" infarction of the bilateral ponto-medullary junction on MRI findings. To the best of our knowledge, giant "heart appearancelike" infarction of the bilateral ponto-medullary junction has not been reported.

MRI findings indicated "heart appearance-like" acute ischemic infarction of the bilateral ponto-medullary junction. DSA findings indicated the VA and BA remained intact. So we speculated that the bilateral ponto-medullary junction infarction might be caused by the deep perforating branch, short circumflex branch of basilar artery of the basilar artery. Combined with the history of the patient, which she had a history of diabetes and hypertension and laboratory tests revealed abnormal lipid metabolism and hyperuricemia on admission, we postulated microatheromatosis affecting the perforator branches of the basilar artery, including basilar artery branch disease, or small artery disease as the underlying mechanism. Arterial supply of brainstem is divided into the anteromedial territory, anterolateral territory, lateral territory, and posterior territory [11]. The "heart appearance-like" sign is considered to appear when the infarct occurs in the anteromedial and anterolateral territories. Since the scheme of vascularization of the pons is identical to that of the medulla [4], we also hold that it should not be surprising to encounter "heart appearance" infarction of the pons [9]. The overall outcome of this type of stroke is poor [10], so we need to early recognition and treatment. Our patient ended up with quadriplegia (upper and lower limbs with grade 2 power), dysarthria, bilateral facial weakness and nasal feeding.

As far as we know, the "heart appearance-like" infraction in bilateral ponto-medullary junction infarction was not reported. Our case also suggests that bilateral ischemic infraction involvement of the medulla and pon is possible even in the context of an intact basilar artery [9].

\section{Abbreviations}

MMI: Medial medullary infarction; MPI: Medial pons infarction; MRI: Magnetic resonance image; DSA: Digital subtraction angiography

\section{Acknowledgements}

The authors thank the patient for allowing us to publish this case report. 


\section{Authors' contributions}

ZHZ and YFW carried out data collection and drafted the manuscript. ZHZ conceived, designed the research and interpreted the data and made critical revisions of the manuscript. WFW, AQL, QYY, ZXP and MFH participated in data collection and interpreted the data. All authors read and approved the final manuscript.

\section{Funding}

Not applicable.

\section{Availability of data and materials}

The datasets used and/or analysed during the current study are available from the corresponding author on reasonable request.

Ethics approval and consent to participate

The principles of the Declaration of Helsinki were followed.

\section{Consent for publication}

Written informed consent was obtained from the patient for publication of this case report and any accompanying images.

\section{Competing interests}

The authors declare that they have no competing interests.

\section{Author details}

'Department of neurology, The first affiliated hospital, School of Clinical Medicine of Guangdong Pharmaceutical University, Guangzhou, Guangdong, China. ${ }^{2}$ Department of Medical Imaging, Guangdong Second Provincial General Hospital, Guangzhou, China.

\section{Received: 15 November 2019 Accepted: 11 March 2020}

Published online: 23 March 2020

\section{References}

1. Toyoda K, Imamura T, Saku Y, Oita J, et al. Medial medullary infarction: analyses of eleven patients. Neurology. 1996;47:1141-7.

2. Kumral E, Afsar N, Kirbas D, et al. Spectrum of medial medullary infarction: clinical and magnetic resonance imaging findings. J Neurol. 2002;249:85-93.

3. Shono $\mathrm{Y}$, Koga $\mathrm{M}$, Toyoda $\mathrm{K}$, Matsuoka $\mathrm{H}$, et al. Medial medullary infarction identified by diffusion-weighted magnetic resonance imaging. Cerebrovasc Dis. 2010;30:519-24.

4. Kumral E, Bayülkem G, Evyapan D. Clinical spectrum of pontine infarction. Clinical-MRI correlations J Neurol. 2002;249:1659-70.

5. Lee ES, Sung KB, Lee TK. Teaching Video Neurolmages: Upbeat and horizontal gaze-evoked nystagmus in bilateral medial medullary infarction. Neurology. 2017;89:e238.

6. Zhang L, Zhang GL, Du JM, et al. Bilateral medial medullary infarction with nondominant vertebral artery occlusion. J Stroke Cerebrovasc Dis. 2015;24: e241-4

7. Maeda M, Shimono T, Tsukahara H, et al. Acute bilateral medial medullary infarction: a unique 'heart appearance' sign by diffusion-weighted imaging. Eur Neurol. 2004;51:236-7.

8. García-Esperón C, López-Cancio E, Martín-Aguilar L, et al. Fluctuating lockedin syndrome as a presentation of a bilateral pontine infarction. Neuroradiol. 2016:29:347-9.

9. Ishizawa K, Ninomiya M, Nakazato Y, et al. "Heart appearance" infarction of the pons: a case report. Case Rep Radiol. https://doi.org/10.1155/2012/ 690903

10. Pongmoragot J, Parthasarathy S, Selchen D, et al. Bilateral medial medullary infarction: a systematic review. J Stroke Cerebrovasc Dis. 2013;22:775-80.

11. Tatu L, Moulin T, Bogousslavsky J, et al. Arterial territories of human brain: brainstem and cerebellum. Neurology. 1996;47:1125-35.

\section{Publisher's Note}

Springer Nature remains neutral with regard to jurisdictional claims in published maps and institutional affiliations.

Ready to submit your research? Choose BMC and benefit from:

- fast, convenient online submission

- thorough peer review by experienced researchers in your field

- rapid publication on acceptance

- support for research data, including large and complex data types

- gold Open Access which fosters wider collaboration and increased citations

- maximum visibility for your research: over $100 \mathrm{M}$ website views per year

At $\mathrm{BMC}$, research is always in progress.

Learn more biomedcentral.com/submission 